\title{
Discharge and force distribution in a sinuous channel with vegetated floodplains during overbank flow
}

\author{
PEDRO J.M. MORETA (IAHR Member), Lecturer, Department of Civil and Environmental Engineering, Brunel University, \\ London, UK \\ Email: pmarmor@ciccp.es (author for correspondence)
}

JUAN P. MARTÍN-VIDE, Professor, Departament d'Enginyeria Civil i Ambiental, Universitat Politècnica de Catalunya, Barcelona, Spain,

Email: juan.pedro.martin@upc.edu

\begin{abstract}
Overbank flow in a sinuous channel with roughened floodplains has been investigated, focusing on the effect of floodplain vegetation on overall flow resistance. The physical model of the Besòs River has allowed analysing the effect of flexible roughness elements which simulate the natural vegetation of rivers. The experimental measurements of horizontal velocities have been used to obtain zonal discharges and forces along a meander wavelength. The results illustrate that although mass transfer is the most important source of energy losses, in rivers with strongly vegetated floodplains the flow resistance increases considerably due to the strong apparent shear forces acting between the main channel and floodplains.
\end{abstract}

Keywords: Apparent shear stress; mass exchange; momentum transfer; overbank flow; sinuous river; vegetated floodplains

\section{Introduction}

Environmental concerns in channelized rivers have called for meandering of the main river channel and growing vegetation on the floodplains (Martín-Vide, 2001). Often, an initial straight encroachment has been turned into a more natural planform, and man-made revetments have been replaced by alluvial materials and native vegetation. These environmental improvements increase flow resistance and, consequently, flood levels. Therefore the flood risk becomes higher after this type of river restoration. River authorities have the responsibility to maintain, or even reduce, flood levels, and researchers need to explore the flow characteristics and how they affect the water levels and river conveyance. Due to these concerns, overbank flow in rivers with floodplains (compound river channels) became a main topic of research in the last decades of the past century.

Sellin (1964) and Zheleznyakov (1971) were some of the first who identified the three-dimensional phenomenon and the strong interaction occurring between the main channel and floodplains in straight compound channels. This turbulent interaction (Townsend, 1968; Wright \& Carstens, 1970) generates internal stresses named as apparent shear stresses. Many authors (Knight \& Demetriou, 1983; Myers, 1978; Wormleaton, Allen, \& Hadjipanos, 1982 and Shiono \& Knight, 1991) investigated the reduction of the total section conveyance due to the effect of apparent shear stresses.

Traditional methods for calculating discharge were based on standard uniform flow formulas, such as the Manning equation, either treating the cross section as a single channel, i.e. single channel method (SCM) or dividing it into independent subsections, i.e. divided channel method (DCM), obtaining the total discharge by summing the discharges in each subsection. The simplification of these methods may give inaccurate estimates for compound open channel flows (Wormleaton et al., 1982), and new methods and formulae were developed in order to reduce uncertainties in discharge estimation (Bousmar \& Zech, 1999; Wormleaton \& Merrett, 1990 and Huthoff, Roos, Augustijn, \& Hulscher, 2008), mainly by introducing friction forces at the main channel and floodplains interface. These methods have been demonstrated to be successful for straight compound channel flows (Fernandes, Leal, \& Cardoso, 2012). 
Overbank flow in straight compound channels has proven to be simpler than in channels which are not parallel (skewed) or even are meandering along the floodplains (Elliott \& Sellin, 1990). Toebes and Sooky (1967) illustrated the complexity of the overbank flow in a meandering channel, which is mainly characterized by a strong expulsion of water from the main channel to the floodplain downstream of the apex section and a strong interaction between the straight floodplain flow and the meandering main channel flow at the cross-over section (in the mid distance between two apex). The main features of this three-dimensional flow were analysed on the meandering compound channel experiments in the Flood Channel Facility (FCF, Series B) by Ervine, Willetts, Sellin, and Lorena (1993) and Sellin and Willetts (1996) and they were graphically synthesized by Sellin, Ervine, and Willetts (1993). Other authors have confirmed these results in small flumes (McKeogh \& Liely, 1989; Sanjou \& Nezu, 2009; Shiono \& Muto, 1998). Most of this work was focused on velocity measurements, concluding that the primary velocity below the floodplain bed level follows the meander channel, whereas above the floodplain it tends to follow the valley direction. These studies formed the basis of new methods for estimating the discharge in meandering channels under overbank flow conditions (Toebes \& Sooky, 1967; Wark, James, \& Achers, 1994; Greenhill \& Sellin, 1993; Rameshwaran $\&$ Willetts, 1999). These methods were developed for channels with uniform bed roughness across the compound section, and they use a horizontal line at the bankfull depth as the main channel and floodplains division, ignoring the influence of upstream and downstream cross-sections into flow.

Overbank flow in natural rivers is also characterized by the roughness difference between the alluvial channel bed and the vegetated floodplains. In the FCF, Wormleaton et al. (2004a) studied the overbank flow in a meandering channel with mobile bed and densely roughened floodplains, showing that the interchange of discharge in the cross-over section is highly influenced by the roughness in the floodplains. As the floodplain roughness increases, the floodplain velocities are reduced and the interaction with the main channel flow is stronger. Shiono, Chan, Spooner, Rameshwaran, and Chandler (2009) confirmed these results in a small channel with different roughness configurations on floodplains. New methods have been developed for taking into consideration the effect of floodplain roughness in different cross-sections by using the vertical separation between the main channel and floodplains (Martin-Vide, López-Querol, \& Moreta, 2004; Wormleaton et al., 2004b).

However, in those works only some features of the flow were investigated, i.e. water level, velocity and secondary flow. Bousmar, Omran, Atabay, and Knight (2009) showed a momentum analysis along a complete wave-length in a meandering channel, yet with the same roughness in floodplains and main channel. In the present paper, the overbank flow in a low sinuous channel with dense flexible vegetation in the floodplains is investigated along a meander wavelength. The aim of this paper is to assess the effect of floodplain roughness and flow depth on the discharge distribution between the main channel and floodplains and on the magnitude of the forces involved in the flow.

\section{Experimental set-up}

The mouth reach of the Besòs River (Barcelona, Spain) is formed by a straight compound section. The environmental restoration of the Besòs River consisted in the meandering of the main channel and re-vegetation of floodplains (Martín-Vide,
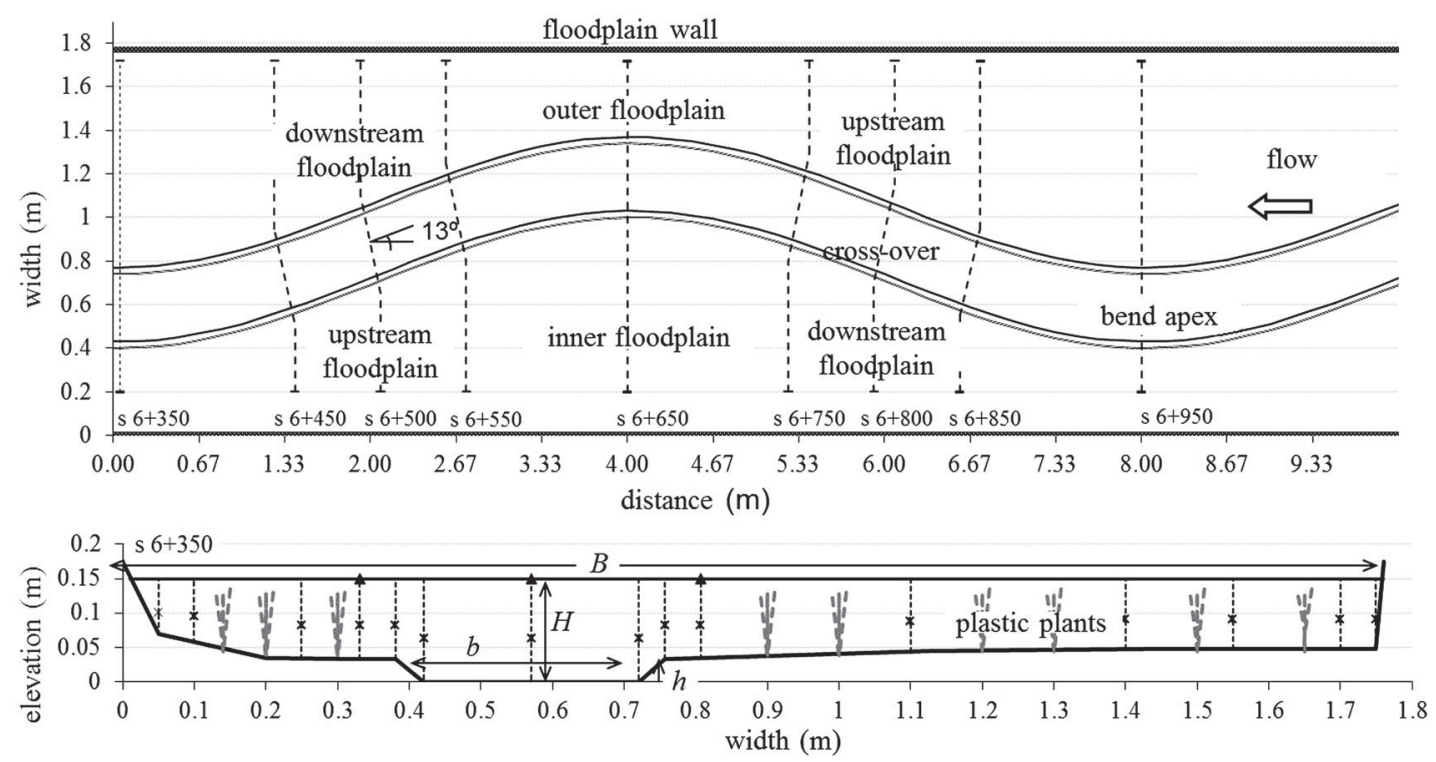

Figure 1 Top: Plan form view of a complete meander wave-length with the 9 measuring cross-sections (from s6 + 350 to s6 + 950). The "upstream floodplain" and "downstream floodplains" are named in relation to the main channel in each cross-section. In the apex the nomenclature changes. Bottom: Typical cross-section of the Besòs scale model, where crosses are points of velocity measurement at $40 \%$ of the local water depth. The plant height is $\approx 0.10 \mathrm{~m}$ 


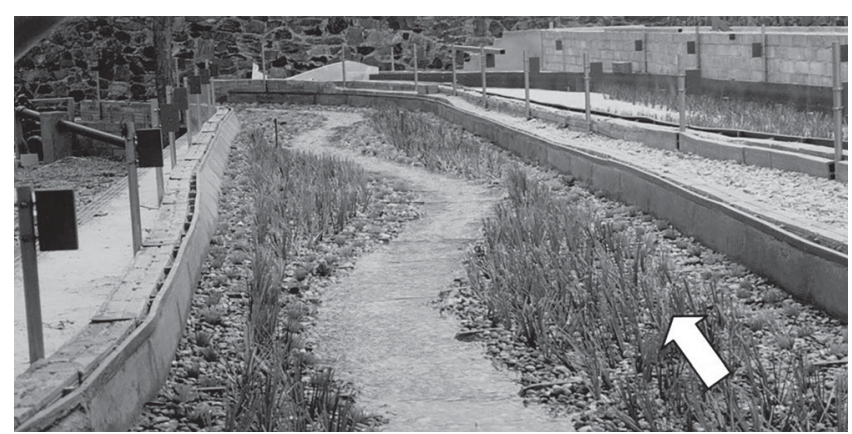

Figure 2 Downstream view of Besòs river model, with the sinuous main channel and the floodplains fully covered by plastic strips (flexible vegetation). The arrow indicates flow direction

2001) of $1 \mathrm{~km}$ length. A physical model of the meandering compound channel (Figs 1 and 2) was carried out in order to analyse the effects of vegetated floodplains in water levels and velocities. Once the project experiments were finished, a detailed campaign of measurements was initiated in the physical model. The main objective of this additional work was the study of the flow characteristics of the overbank flow in rivers under nearly natural conditions: a meandering main channel with vegetated floodplains.

The geometry of the physical model consisted of a low sinuous main channel with adjacent floodplains limited by straight and parallel walls (Figs 1 and 2). The flume was $18.70 \mathrm{~m}$ long and $1.76 \mathrm{~m}$ width. However, the study length was reduced to $8.00 \mathrm{~m}$, comprising one complete meander wavelength (between sections $s 6+950$ and s6 +350 in Fig. 1). The mean slope of the main channel in the study reach was 0.0090 , with a sinuosity of 1.05 , and the mean slope on the floodplains being 0.0095 . The main channel section was trapezoidal, the bed was $0.330 \mathrm{~m}$ wide and $0.035 \mathrm{~m}$ deep ( $h$ in Fig. 1), and the margins slope was $2 \mathrm{H}: 1 \mathrm{~V}\left(60^{\circ}\right)$. The floodplains were quasi-horizontal with a slight slope towards the main channel. These geometrical features are shown in Fig. 1 and summarized in Table 1. Eight cases have been tested: four different discharges for each configuration, with no plants and with plants. As the other geometrical parameters remain invariable the only differences are the roughness and the depth ratio.

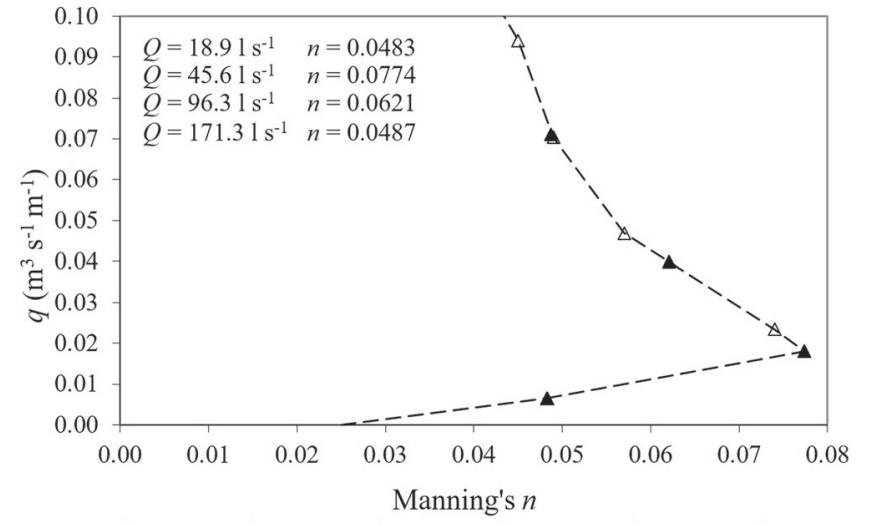

Figure 3 Manning coefficients used for the discharges with plants (black triangles), interpolated from independent experiments (white triangles)

The main channel and the floodplains were filled with uniform gravel $\left(d_{50}=20 \mathrm{~mm}\right)$, to achieve a uniform roughened surface. This sediment type is chosen to represent prototype rivers with strong bed roughness due to combination of gravels, vegetation, weeds, islands and other bed irregularities. In the experiments with vegetation, the floodplains were covered with flexible plastic plants. These plants are intended to simulate the roughness of Phragmites australis, natural vegetation of many Mediterranean rivers (Mauchamp, Chauvelon, \& Grillas, 2002). The $10 \mathrm{~cm}$ high plastic plants were manually inserted into the gravel with a density of 100 plants per $\mathrm{m}^{2}$ (one plant in the middle of $10 \mathrm{~cm}$ square). The gravel and strips roughness was determined in independent experiments carried out in a straight single channel (Vionnet, Tassi, \& Martín Vide, 2004), in which the same unit discharges and slope as in the physical model were tested. The Manning's roughness coefficient of the gravel bed $\left(d_{50}=20 \mathrm{~mm}\right)$ was estimated as $n=0.025$, while the roughness of the flexible plastic plants of the floodplains was found to depend on unit discharge (Fig. 3). When the flow rate was increased, from Q45wp to Q171wp, the plants were completely submerged and roughness decreased due to their flexibility (Kouwen, 1990). While the plants were not submerged (Q18wp and Q45wp) the behaviour was more similar to rigid vegetation (Petryk \& Bosmajian, 1975).

Table 1 Main parameters of the experiments. Total width $(B)$, main channel bed width $(b)$, total depth $(H)$ and bankfull depth $(h)$. Dimensions in metres

\begin{tabular}{|c|c|c|c|c|c|c|c|c|c|c|}
\hline Typology & $\begin{array}{l}\text { Series } \\
\text { name }\end{array}$ & $b / h$ & $B / b$ & $\begin{array}{l}\text { Main channel section } \\
\text { (bank slope) }\end{array}$ & $\begin{array}{c}\text { Floodplain } \\
\text { roughness }\left(n_{f}\right)\end{array}$ & $\begin{array}{l}\text { Floodplain } \\
\text { width }\left(B_{f}\right)\end{array}$ & $\begin{array}{l}\text { Bankfull } \\
\text { depth }(h)\end{array}$ & Slope & $(H-h) / H$ & $\begin{array}{c}\text { Discharge } \\
\left(1 \mathrm{~s}^{-1}\right)\end{array}$ \\
\hline No plants (np) & $\begin{array}{l}\text { Q18np } \\
\text { Q45np } \\
\text { Q96np } \\
\text { Q171np }\end{array}$ & 9.8 & 5.4 & $\begin{array}{l}\text { Trapezoidal } \\
(1 \mathrm{H}: 2 \mathrm{~V})\end{array}$ & Gravel: 0.025 & $\begin{array}{l}0.4 \times 1+1.0 \times 1 \\
\text { bend apex section }\end{array}$ & 0.035 & 0.0095 & $\begin{array}{l}0.493 \\
0.625 \\
0.714 \\
0.780\end{array}$ & $\begin{array}{c}18.96 \\
45.56 \\
96.33 \\
171.26\end{array}$ \\
\hline With plants (wp) & $\begin{array}{l}\text { Q18wp } \\
\text { Q45wp } \\
\text { Q96wp } \\
\text { Q171wp }\end{array}$ & 9.8 & 5.4 & $\begin{array}{l}\text { Trapezoidal } \\
(1 \mathrm{H}: 2 \mathrm{~V})\end{array}$ & $\begin{array}{rr} & 0.0483 \\
\text { Flexible } & 0.0774 \\
\text { plants: } & 0.0621 \\
& 0.0487\end{array}$ & $\begin{array}{l}0.4 \times 1+1.0 \times 1 \\
\text { bend apex section }\end{array}$ & 0.035 & 0.0095 & $\begin{array}{l}0.529 \\
0.693 \\
0.783 \\
0.822\end{array}$ & $\begin{array}{c}18.96 \\
45.56 \\
96.33 \\
171.26\end{array}$ \\
\hline
\end{tabular}



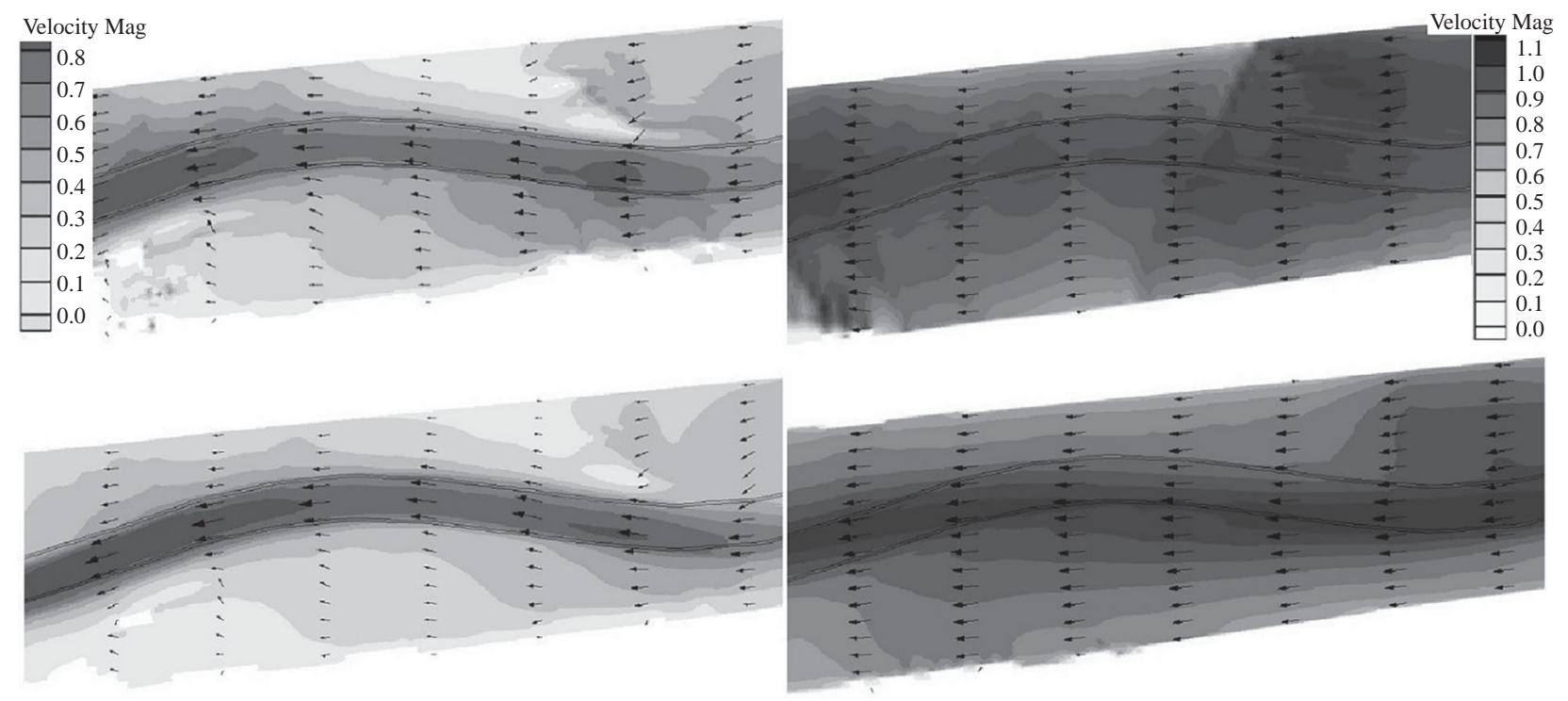

Figure 4 Flow velocities in magnitude (the darker the faster) and direction (velocity arrows) in a meander wavelength $(\mathrm{s} 6+500-\mathrm{s} 6+950)$. The maximum velocity line (darker) tends to follow the walls in high discharges, Q171np (top right) and Q171wp (bottom right), whereas in low discharges, Q18np (top left) and Q18wp (bottom left), tend to follow the channel banks

Discharges were supplied at the upstream inlet and fixed by using a thin-plate V-notch weir as a downstream outlet. Water levels were measured directly with a point gauge located on an instrument carriage that could be moved along the flume. The measurements were made at three points (one in the main channel and one in each floodplain) for the selected nine crosssections (Fig. 1). The velocities were measured at those cross sections, located and spaced as shown in Fig. 1. These velocities were recorded by using a Valeport 2D electromagnetic probe moving through the cross section at a $40 \%$ of the local depth in each point of measurement, and every measurement was repeated three times. The mean of the three values was assumed to be an approximate measurement of the local depth-averaged velocity, called Velocity in this paper. In Fig. 1 the velocity measurements are crosses, and water levels are black triangles; see Vionnet et al. (2004) for more details.

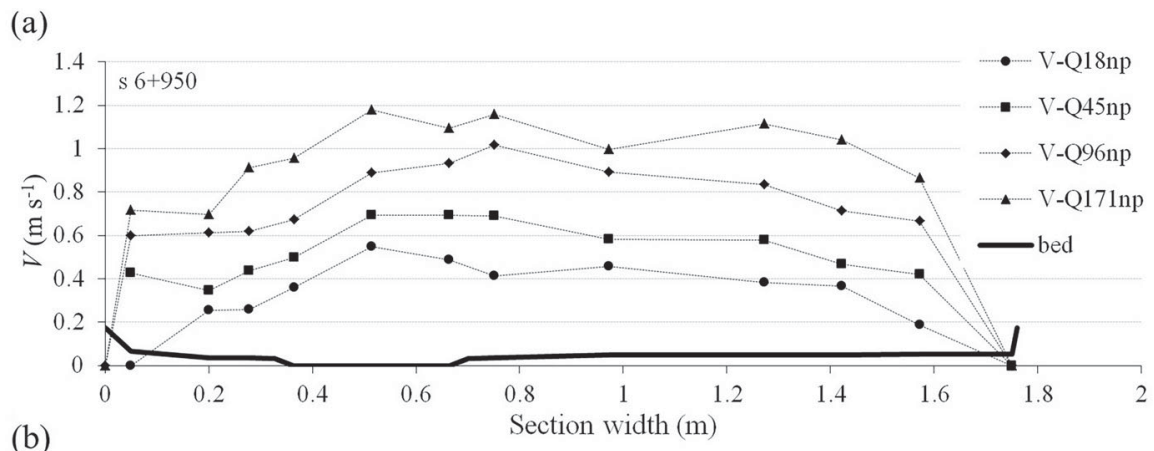

(b)

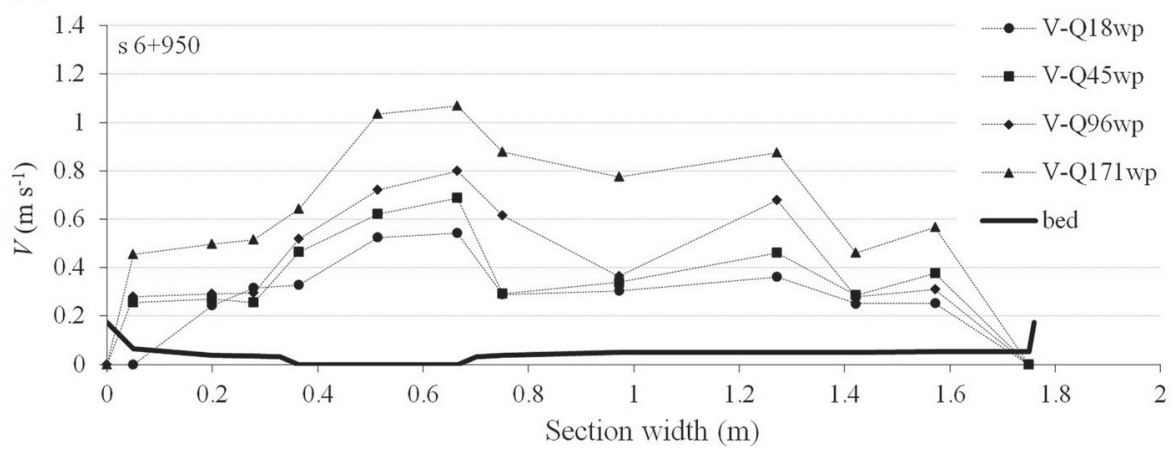

Figure 5 Cross-section distribution of the streamwise velocity $(V)$, measured at $40 \%$ of local depth, across the apex section s6 +950 in the tests (a) with no plants, and (b) with plants 

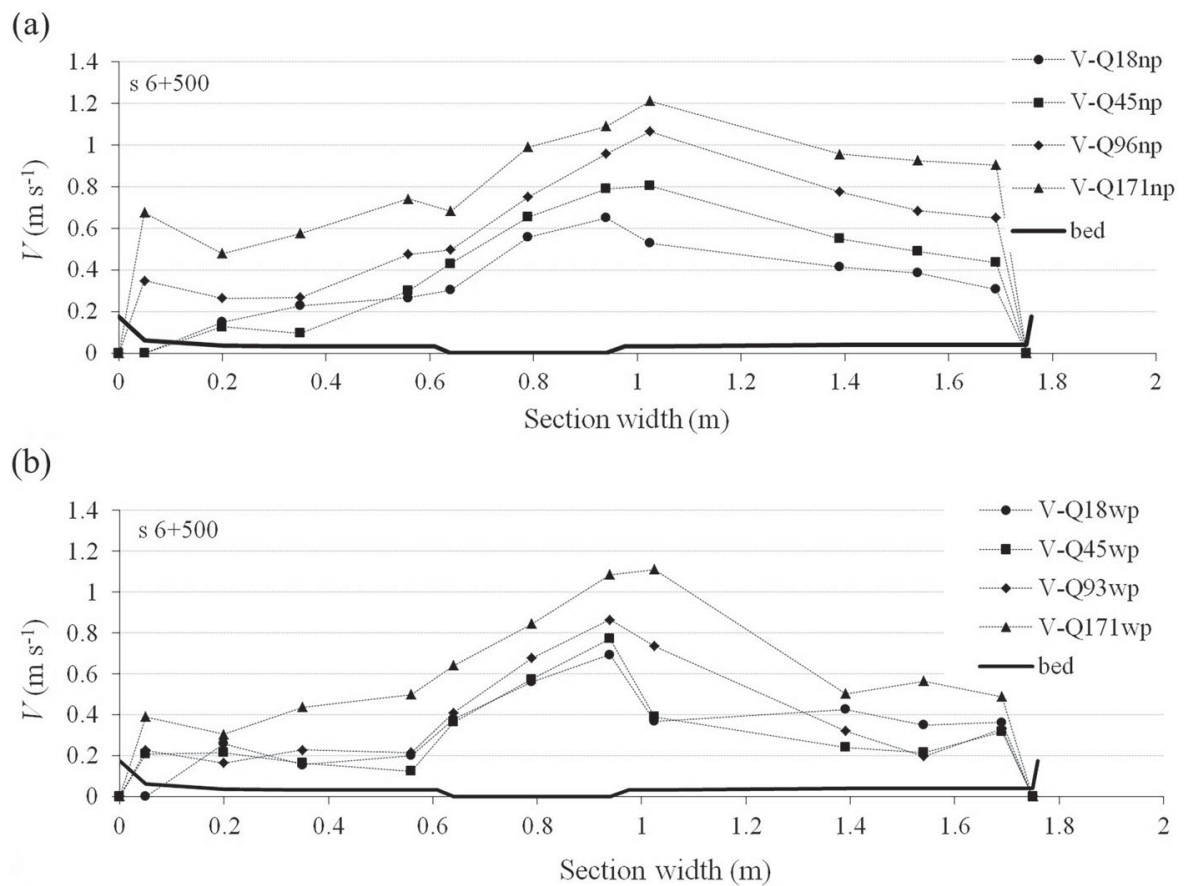

Figure 6 Cross-section distribution of the streamwise velocity $(V)$ across the crossover section s6 +500 , in the tests (a) with no plants, and (b) with plants

\section{Experimental data: discharges, water levels and velocities}

The velocity measurements are summarized in Fig. 4, which shows the direction and relative magnitude of the velocity on one meander wavelength for the lowest and largest discharges. This figure confirms some significant flow characteristics described by other authors: (1) a sinuous flow above the main channel in case of a shallow overbank; (2) a straight flow oriented by the walls in case of a deep overbank; (3) the maximum velocity filaments in the main channel tend to follow parallel to the floodplain walls as the flow depth increases.

The velocity distribution across sections $\mathrm{s} 6+950$ (upstream bend apex) and s6 +500 (downstream cross-over; Fig. 1) is shown in Figs 5 and 6. Four lines are plotted in these figures, one for each discharge. It is seen that in the cases with no plants the maximum velocity falls clearly within the main channel only for the lowest discharge. In the three highest discharges the maximum velocity occurs on the inner floodplain (right in Fig. 5) very close to the main channel bank, as it was shown by Sellin et al. (1993) for relative depths, $(H-h) / H>0.45$, where $H$ is the water depth in the main channel and $h$ is the depth in bankfull depth. The low velocities on the outer floodplain increase across the main channel to reach higher velocities in the inner floodplain. In the four discharges with plants the maximum velocities fall within the main channel, very close to the inner bank. The flow is faster in the channel than in the floodplains and slightly faster in the inner than in the outer floodplain (left in Fig. 4). For the crossover section (Fig. 6), similar trends are shown. However, the difference between the highest and the lowest velocities is much larger. Velocities on the downstream expanding floodplain (right in Fig. 6) are higher than those on the downstream contracting (or upstream expanding) floodplain (left in Fig. 6). The velocity in the main channel increases sharply from the left to the right bank.

It is also noticeable from Figs 5 and 6 that the trend of the velocity distribution across the section is similar for the four discharges of each graph, in spite of two obvious effects: (1) as the discharge increases velocities increase as well; (2) velocities with plants are affected by the variation of roughness with submergence (Table 1). The effect of a Manning's $n$ varying due to the bending of the plants is illustrated in Fig. 7 in terms of crosssectional mean velocities. The trend of the curve for cases with no plants fits the increase of flow area but the curve with plants clearly reflects the point scattering due to the varying $n$ values. Another similar description of flow conveyance with and with no plants is given by the stage-discharge curve of Fig. 8 .

\section{Analysis of experimental results}

\subsection{Discharge and velocity distribution along a meander wavelength}

The first question for discharge estimation using traditional compound channel methods is the choice of the division lines between main channel and floodplains. The interaction between the straight floodplain flow and the sinuous main channel flow generates a strong horizontal shear at the crossover section. For this reason a horizontal line at the bankfull level has been used as the division line by some researchers (Greenhill \& Sellin, 1993). However, Martin-Vide et al. (2004), in a meandering compound 


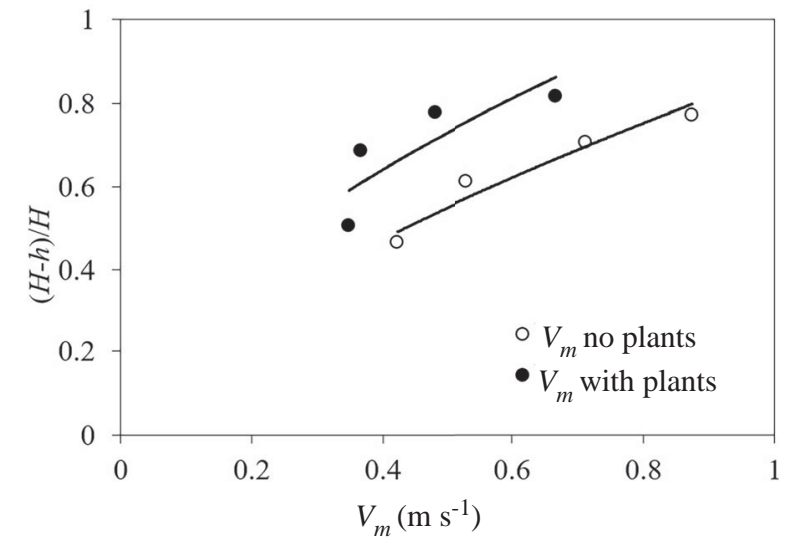

Figure 7 Variation of the mean velocity $\left(V_{m}\right)$ with relative depth for the four discharges with no plants and with plants. $V_{m}$ is the discharge divided by the average flow area of the nine cross-sections in Fig. 1

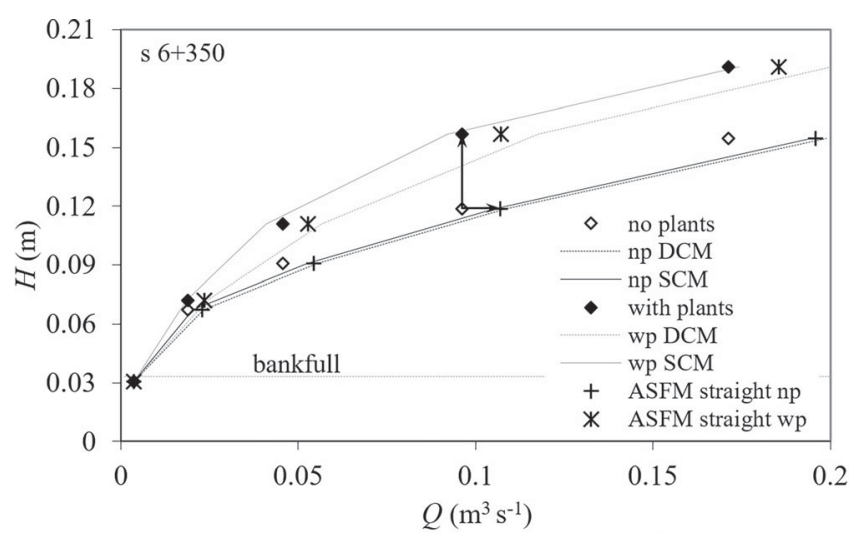

Figure 8 Stage-discharge curves for discharges with plants (wp) and no plants $(\mathrm{np})$ in cross-section $\mathrm{s} 6+350$. Rhomboids are observed data. Crosses and stars are depths computed by ASFM for an equivalent straight channel (Moreta \& Martin-Vide, 2010) with the same area and wetted perimeter. Comparison with depths calculated by DCM and SCM (lines). Arrows show the difference between vegetated and non-vegetated floodplains (vertical) and between sinuous and straight main channel (horizontal)

channel with roughened floodplains, showed that a vertical division line is more adequate, and Wormleaton et al. (2004b) in the FCF experiments with a meandering and mobile bed main channel (series C) concluded that when the floodplain roughness is higher than the main channel roughness, the horizontal division line does not represent the physical phenomenon. They suggested that a vertical division line might describe the flow more realistically.

In this work, the observed experimental discharge is compared with calculations based on separating the main channel and floodplains by horizontal (DCM-h) and vertical (DCM-v) division lines, and summing the main channel and floodplain discharges obtained by Manning's equation in each subarea and ignoring losses at the division lines. The parameter $F^{*}$ defined by Ervine et al. (1993) as:

$$
F^{*}=\frac{\text { total observed discharge }}{\text { total calculated discharge }(\mathrm{DCM})}
$$

is plotted in Fig. 9. In cases with no plants, values of $F^{*}$ around 0.8 are obtained with DCM-h, suggesting significant interaction energy losses. However, in the cases with plants, the values of $F^{*}$ higher than unity imply an artificial energy gain due to the interaction in the horizontal line. The values of $F^{*}$ obtained with the DCM-v (Fig. 9) confirm that the vertical division line provides a sound basis when the velocity gradient between main channel and floodplain is large, and particularly for these tests in which the floodplain roughness is greater than the main channel roughness. In cases with no plants, though, the method with vertical divisions gives values of $F^{*}$ slightly higher than with the horizontal division, pointing out a stronger underestimation of interaction losses with the DCM-h. Figure 9 also shows that with the horizontal division the losses due to main channel and floodplain interaction are higher in the case with no plants than in the case with plants, which is also unrealistic. The analysis of $\mathrm{F}^{*}$ confirm that DCM-v gives a better insight of flow resistance due to main channel and floodplain interaction, particularly in cases with rough floodplains.

Assuming then the vertical separation lines, the discharge in the main channel and the floodplains was calculated by integration of velocity data across each of these zones. The mean velocity in each sub-zone is calculated dividing the discharge by the flow area. Figure 10 shows the discharge fraction of the main channel and floodplains averaged over the nine cross sections (Fig. 1). It is seen that as the depth increases the fraction of the floodplain discharge increases as well. In the discharges with plants the proportion of floodplain discharge is lower than with no plants (more than 10\%) for the same relative depth.

The value of the main channel discharge along a meander wavelength is important in order to quantify the exchange of discharge between main channel and floodplains. This exchange

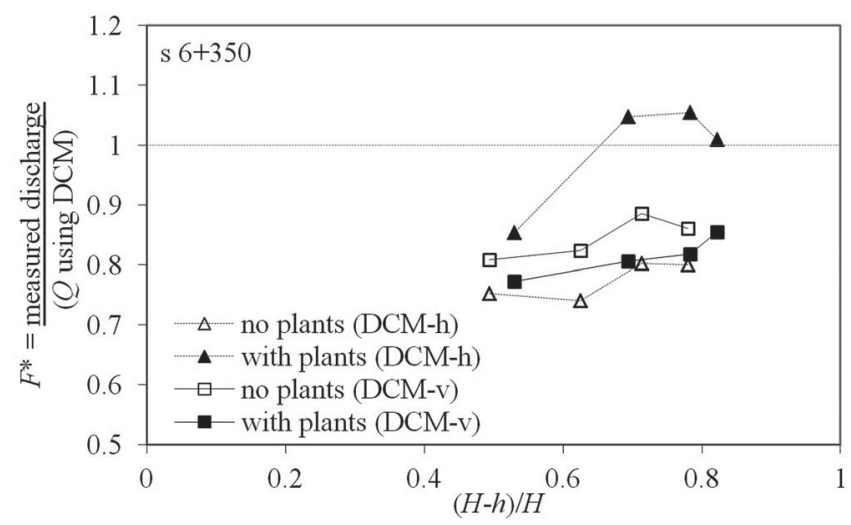

Figure 9 Variation in $F^{*}$ (Eq. 1), with depth ratio for horizontal (DCM-h) and vertical (DCM-v) interfaces in the cases with no plants and with plants (downstream apex section s6 +350 ) 


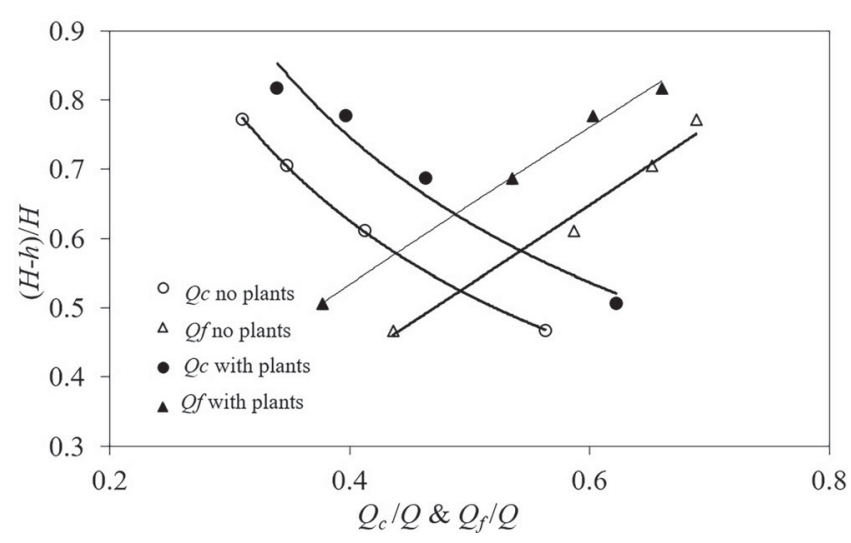

Figure 10 Proportion of discharge for main channel $\left(Q_{c}\right)$ and floodplains $\left(Q_{f}\right)$ for both the cases with no plants and with plants (averaged values for the nine sections)

varies from section to section depending on whether the floodplain alignment intersects the sinuous main channel (crossover sections) or not (apex sections). Figure 11 shows the main channel discharge from section $s 6+950$ to $s 6+350$ for the eight discharges, with and with no plants. The discharge in the main channel increases in the sections located just downstream the bend apex $(s 6+950, s 6+650)$ where it reaches a maximum. Conversely, this discharge decreases to the sections just downstream the crossovers $(s 6+800$ and $s 6+500)$, where it reaches a minimum. From these sections $(\mathrm{s} 6+750$ and $\mathrm{s} 6+450)$ the discharge increases to the apex section again. This behaviour is more evident in the highest discharges.

It follows from these results, that in the bend apex, the upstream floodplain (outer) incorporates water to the main channel, while the main channel starts expulsing water to the downstream floodplain (inner). Altogether, the discharge in the main channel is growing in the bend apex. In the crossover sections a similar reasoning can be made but with an expulsion of discharge along the main channel. A balance between water received and water delivered is achieved in some points (maximum and minimum in Fig. 11). It can be concluded that in the crossover reach (sections $s 6+850, s 6+800$ and $s 6+750$ or sections $s 6+550, s 6+500$ and $s 6+450$ in Fig. 1) the main channel delivers more discharge downstream than it receives from upstream, whereas in the bend reach (sections $s 6+750$, $s 6+650$ and $s 6+550$ in Fig. 1), the opposite prevails.

It is also noticeable from Fig. 11 that the form of the discharge distribution along a meander wavelength is similar in cases with plants and with no plants. This means that the exchange of discharge occurs in the same manner. However, in the cases with plants the difference between the maximum and the minimum discharge in the main channel is larger for the same discharge, i.e. in cases with plants the flow exchange is greater than with no plants. As the inlet discharge is the same, there are only two possible reasons for this behaviour: the roughness difference on the floodplains or the depth difference. In order to confirm this, the discharge exchange in tests Q96wp $((H-h) / H=0.783)$ and Q171np $((H-h) / H=0.780$; Table 1, Fig. 8) is analysed. These cases have different floodplain roughness but same relative depth. From Table 2, the difference between the maximum and minimum main channel discharge for these tests is $7.61 \mathrm{~s}^{-1}$ (Q96wp) and $8.41 \mathrm{~s}^{-1}$ (Q171np), i.e. $8 \%$ and $5 \%$ of the total discharge. So then for the same water level, a higher discharge exchange is found in cases with plants than with no plants, meaning that the increase of discharge exchange is promoted by the increase of floodplain roughness.

In addition to this increase in discharge exchange, vegetation reduces floodplain conveyance and changes the main channel/floodplain interaction. For the same discharge a higher roughness on the floodplains increases water levels and so the flow area between the main channel and floodplains. Moreover, the main channel discharge becomes higher, thus increasing the mass of water prone to be exchanged to the floodplain. In order to explain the differences in the interaction between main channel and floodplains, Fig. 12 shows the mean velocity in main channel and floodplains for all the relative depths with and with no plants. These are the mean velocities in the main channel and floodplains as an average of the nine sections between $\mathrm{s} 6+950$ and $\mathrm{s} 6+350$.

It is worth noting from Fig. 12 that in the cases with plants the main channel velocity is almost double the floodplain velocity while in the cases with no plants the velocities in the main channel and floodplains are more similar. Besides, the main channel

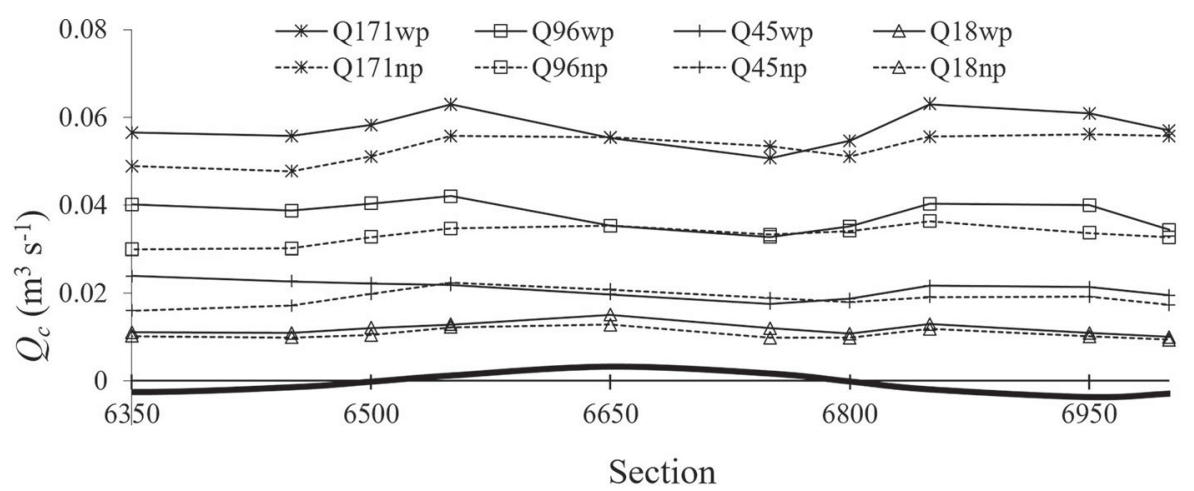

Figure 11 Main channel discharge $\left(Q_{c}\right)$ variation along a meander wavelength (from s6 +950 to $s 6+350$ ) 
Table 2 Main channel discharges, highest (bold) and lowest (underlined) discharges in a wavelength. Cross sections are shown in Fig. 1

\begin{tabular}{|c|c|c|c|c|c|c|c|c|}
\hline \multirow[b]{2}{*}{ Cross section } & \multicolumn{4}{|c|}{ Main channel discharge with no plants $\left(1 \mathrm{~s}^{-1}\right)$} & \multicolumn{4}{|c|}{ Main channel discharge with plants $\left(1 \mathrm{~s}^{-1}\right)$} \\
\hline & Q18np & Q45np & Q96np & Q171np & Q18wp & Q45wp & Q96wp & Q171wp \\
\hline s6 + 950 (apex) & 10.21 & 19.29 & 33.69 & 56.24 & 10.89 & 21.41 & 40.07 & 60.99 \\
\hline$s 6+850$ & 11.93 & 19.17 & 36.35 & 55.63 & 12.95 & 21.71 & 40.30 & 63.09 \\
\hline s6 +800 (crossover) & 9.87 & $\underline{18} . \underline{00}$ & 34.15 & $\underline{51} . \underline{20}$ & $\underline{10} . \underline{78}$ & 18.71 & 35.21 & 54.75 \\
\hline$s 6+750$ & $\underline{9} . \underline{79}$ & 18.96 & $\underline{33} . \underline{29}$ & $\overline{53.51}$ & 12.03 & $\underline{17} . \underline{65}$ & $\underline{32} . \underline{82}$ & $\underline{50} . \underline{80}$ \\
\hline s6 + 650 (apex) & $12 . \overline{86}$ & 20.88 & $\overline{35.40}$ & 55.54 & 15.14 & $\overline{19} . \overline{77}$ & $\overline{35.38}$ & $\overline{55.42}$ \\
\hline$s 6+550$ & 12.29 & 22.40 & 34.69 & 55.79 & 12.90 & 21.92 & 35.38 & 63.07 \\
\hline s6 +500 (crossover) & 10.48 & 19.81 & 32.76 & 51.17 & 12.11 & 22.30 & 40.42 & 58.38 \\
\hline$s 6+450$ & $\underline{9} . \underline{93}$ & 17.23 & 30.17 & $\underline{47} . \underline{83}$ & $\underline{10} . \underline{96}$ & $\underline{22.75}$ & $\underline{38} . \underline{76}$ & $\underline{55} . \underline{84}$ \\
\hline s6 +350 (apex) & $1 \overline{0 .} \overline{25}$ & $\underline{16} . \underline{05}$ & $\underline{30} . \underline{00}$ & $\overline{48 .} \overline{96}$ & $\overline{11.05}$ & $\overline{23.91}$ & $\overline{40} . \overline{15}$ & $\overline{56 . \overline{55}}$ \\
\hline
\end{tabular}

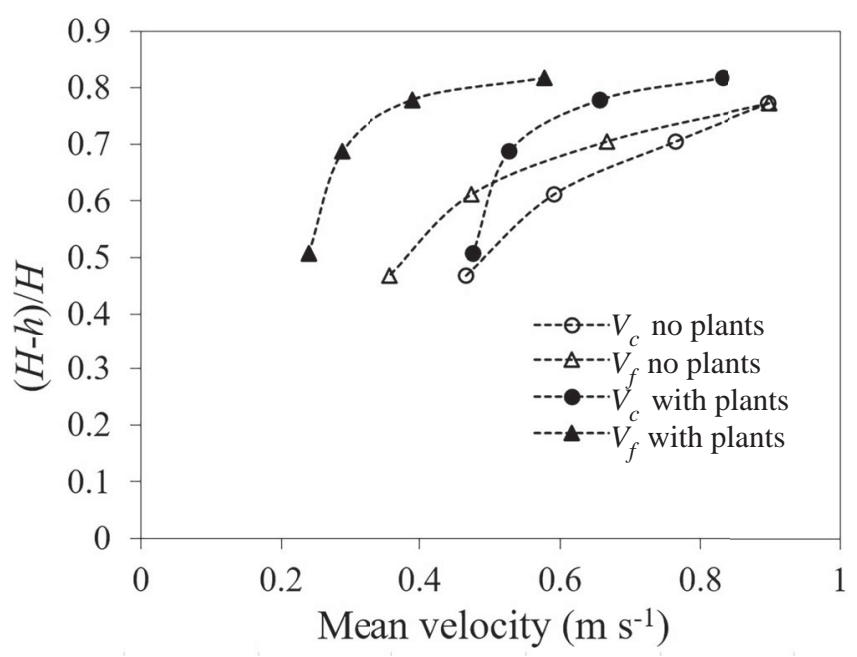

Figure 12 Mean velocities in the main channel $\left(V_{c}\right)$ and floodplains $\left(V_{f}\right)$ against the relative depth

velocities with no plants are higher than with plants, especially in tests Q45wp and Q96wp, where the difference between the roughness in the floodplain and in the main channel is larger than in Q18wp and Q171wp (Table 1). This means that as the floodplain roughness increases with respect to that on the main channel, the velocity in the main channel tends to decrease. The reason is that the interaction between the main channel and floodplains mainly varies with the roughness ratio between floodplain and main channel. It can be concluded then that the flow area it is not the most important factor for the discharge exchange, but the velocity gradient between the main channel and floodplain, which is a consequence of the roughness ratio and the depth ratio.

\subsection{Apparent shear force and momentum balance}

In order to evaluate the forces acting between the sinuous main channel and the left and right floodplains, three separated control volumes $(c, l$ and $r$ ) are defined as illustrated in Fig. 13. The main channel and floodplains are isolated by the imaginary vertical lines which join the channel banks with the water surface. The upstream and downstream boundaries of the control volumes are planes perpendicular to the main flow direction (parallel to floodplain walls). These boundaries are located at each measurement cross-section. The lateral boundaries are the floodplain walls and the vertical interfaces defined in Fig. 13, which separate the flow in three zones: left floodplain, main channel and right floodplain.

The forces and momentum fluxes acting in the control volumes are: the pressure forces on upstream and downstream planes, the component of the water weight, the bed shear resistance, and the apparent shear force on the vertical interfaces. The principle of the momentum conservation for steady flow (2nd Newton's law), states that the net rate of momentum flux on each control volume equals the sum of external forces, i.e. the body forces (gravity) and surface forces (friction and pressure) acting at the control volume. As the flow is quasi-uniform, the water surface can be assumed to be parallel to bed, then pressure forces are in equilibrium and the momentum balance in the flow direction is thus written as:

$$
(M o m)_{2}-(M o m)_{1}-(M o m)_{c f}=W-\tau_{b} P_{w} d+(A S F)_{i}
$$

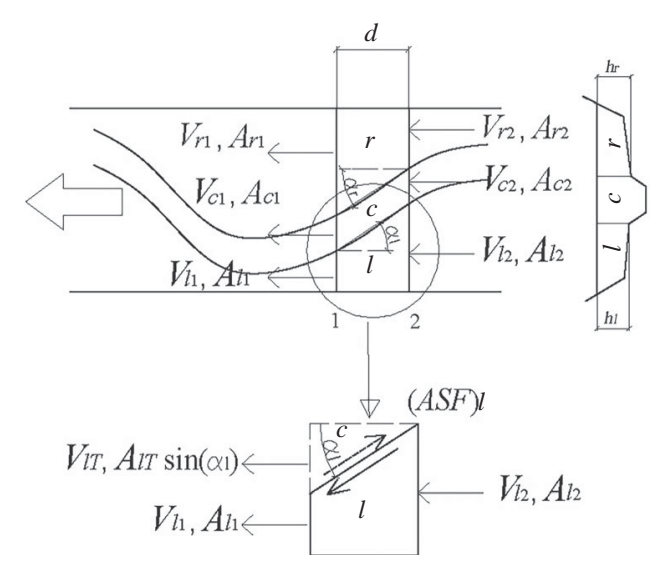

Figure 13 Plan diagram of the control volumes $(c, l$ and $r$ ) for the momentum balance (top). Control volume for left floodplain with forces (bottom) 
where $W$ is the water weight component in the flow direction, $(A S F)_{i}$ is the apparent shear force acting at the vertical interfaces, $\tau_{b}$ is the bed shear stress, $P_{w}$ is the wetted perimeter and $d$ is the perpendicular distance between sections 2 and 1 (Fig. 13). The uniform flow hypothesis (water slope parallel to the bottom) cancels the two pressure terms. The net rate of momentum between sections 2 and 1 is evaluated as the difference between the flux of momentum entering the control volume, $(M o m)_{2}$ in section 2, and the flux of momentum out of the control volume, $(M o m)_{c f}$ through the main channel-floodplain interface plus $(M o m)_{1}$ through section 1. For each control volume these three momentums $(M o m)_{1},(M o m)_{c f}$ and $(M o m)_{2}$ are calculated as:

$$
\begin{aligned}
(\text { Mom })_{1} & =\frac{\text { mass }}{\text { time }} V_{1}=\rho \frac{\text { volume }}{\text { time }} V_{1}=\rho \beta_{1} Q_{1} V_{1}=\rho \beta_{1} A_{1} V_{1}^{2} \\
(\text { Mom })_{c f} & =\frac{\text { mass }}{\text { time }} V_{l T}=\rho \frac{\text { volume }}{\text { time }} V_{l T}=\rho Q_{l T} V_{l T}=\rho A_{l T} V_{l T}^{2} \\
(\text { Mom })_{2} & =\frac{\text { mass }}{\text { time }} V_{2}=\rho \frac{\text { volume }}{\text { time }} V_{2}=\rho \beta_{2} Q_{2} V_{2}=\rho \beta_{2} A_{2} V_{2}^{2}
\end{aligned}
$$

in which subscripts 1 and 2 indicate the downstream and upstream sections, respectively, subscript $l T$ indicates the
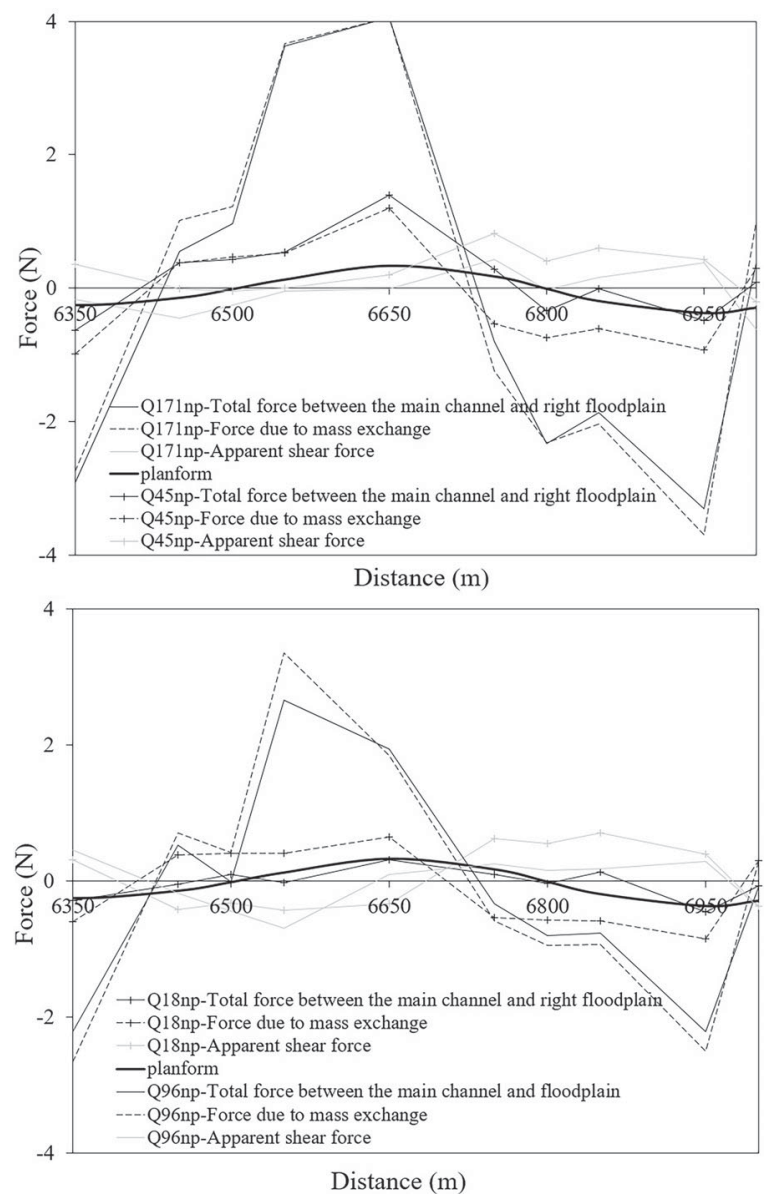

Figure 14 Force and momentum balance along a meander wavelength between the main channel and the right floodplain in the discharges with no plants vertical plane which separates the main channel and the floodplain (either left or right), $\beta$ is the Boussinesq or momentum correction coefficient, $A$ is the flow area, $V$ is the flow velocity, $\rho$ is the water density, and $Q$ is the discharge passing through each plane. The Boussinesq coefficients $\left(\beta_{1}\right.$ and $\left.\beta_{2}\right)$ are assumed to be 1 . The momentum balance, the first term in Eq. (2), is thus written as:

$$
(\mathrm{Mom})_{2}-(\mathrm{Mom})_{1}-(\mathrm{Mom})_{c f}=\rho A_{2} V_{2}^{2}-\rho A_{1} V_{1}^{2}-\rho A_{l T} V_{l T}^{2}
$$

The bed shear force and the weight can be expressed in terms of the friction and bed slopes and the momentum balance for each control volume (main channel and right and left floodplain) from Eq. (2), may then be written as:

$$
\begin{aligned}
& \rho g A_{2} V_{2}^{2}-\rho g A_{1} V_{1}^{2}-\rho g A_{l T} V_{l T}^{2} \\
& \quad=\rho g(V o l) S_{o}-\rho g(V o l) S_{f}+(A S F)_{i}
\end{aligned}
$$

where $S_{o}$ is the bed slope, $S_{f}$ is the friction slope and $(\mathrm{Vol})$ is the control volume, which is obtained by multiplying the distance between sections, $d$, and the averaged area between sections 1 and 2. The apparent shear forces in each subzone, $(A S F)_{i}$, are the turbulent interaction forces at the main channel and floodplains vertical interfaces. In prismatic compound channels, where the main channel and floodplains flows are parallel, this force is generated only by the turbulent shear layer due to the velocity gradient at the vertical interface. In meandering compound channels an additional momentum transfer, (Mom) $)_{c f}$, appears due to the net mass transfer as water flows either off or onto the floodplain. The momentum terms in the left side of Eq. (5) can be computed directly from the velocity data. Therefore, the apparent shear force is the only unknown in the momentum equation, Eq. (5), being easy to solve. The recording errors are then included in the value of $(A S F)_{i}$.

Following Martin-Vide et al. (2004) and Bousmar et al. (2009), the momentum balance in a meander wavelength is presented as in Figs 14 and 15 for the discharges with no plants and with plants respectively. The apparent shear forces are calculated as the difference between the total forces and momentum fluxes. It can be seen in Fig. 14 that in the highest discharges, Q171np and Q96np, the forces due to the mass exchange between main channel and floodplain, $(M o m)_{c f}$, are much higher than the apparent shear forces, $(A S F)_{i}$. However, in the discharge Q45np the difference between the two forces is reduced and in the lowest discharge, Q18np, both forces are similar. Quantitatively, the total force, obtained as the sum of the apparent shear force and the mass exchange force, increases as the total discharge increases, from a value of $\pm 0.5 \mathrm{~N}$ for Q18np up to $\pm 4.0 \mathrm{~N}$ for Q171np. This is mainly due to the exchange of discharge between the main channel and the floodplains as the value of the apparent shear force is between $\pm 0.5 \mathrm{~N}$ for Q171np and $\pm 1.0 \mathrm{~N}$ for $\mathrm{Q} 18 \mathrm{np}$, being lower for highest discharges.

In order to compare the influence of floodplain vegetation into the momentum balance, Fig. 15 shows the same results 

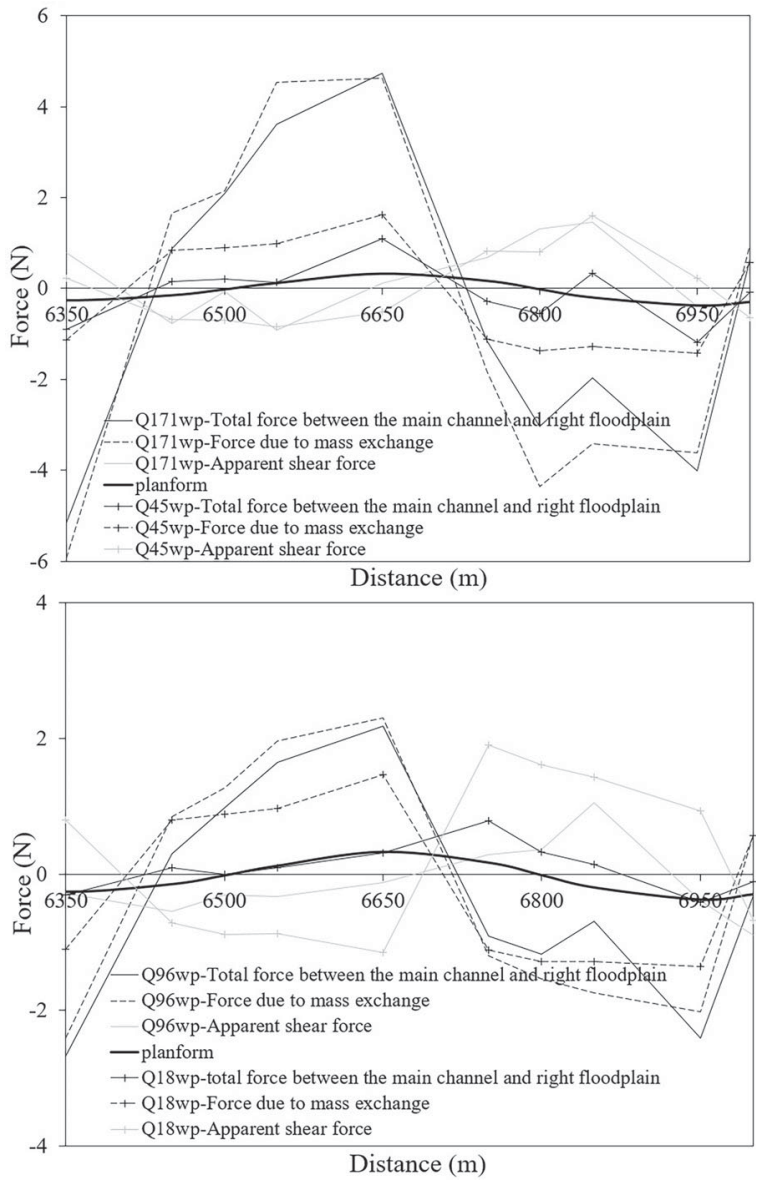

Figure 15 Force and momentum balance along a meander wavelength between the main channel and the right floodplain in the discharges with plants

as Fig. 14 but for discharges with plants. As it happens in the discharges with no plants, in the two highest discharges Q171wp and Q96wp, the forces due to the mass exchange are much greater than the apparent shear forces. However, in the Q45wp test the two forces become equal while in the Q18wp the apparent shear force is higher in all the sections. The shape of forces distribution along the meander wavelength in Fig. 15 is similar to the case with no plants (Fig. 14). The total force in the discharges with plants increases as the total discharge increases, from $\pm 0.7 \mathrm{~N}$ for Q18wp up to $\pm 4.6 \mathrm{~N}$ for Q171wp. This is mainly due to the exchange of discharge between the main channel and the floodplains, as the value of the apparent shear force decreases from $\pm 1.9 \mathrm{~N}$ for Q18wp to $\pm 1.0 \mathrm{~N}$ for Q171wp, being lower for the highest discharges. Figures 14 and 15 show the forces acting at the interface between the main channel and the right floodplain. The forces acting at the main channel-left floodplain interface have the same absolute value but opposite sign.

From this analysis, it can be concluded that the magnitude of the forces due to the mass exchange and to the turbulent shear is affected by the floodplain roughness. Figure 16 compares the same forces two of the cases with and with no plants, Q96 and Q45, showing that the total force is similar in both configurations. However, the influence of the mass exchange forces and the apparent shear forces is different. The apparent shear forces in cases with plants are higher than $\pm 1.0 \mathrm{~N}$ for all the discharges, while in the cases with no plants these values are between $\pm 0.5 \mathrm{~N}$ and $\pm 1.0 \mathrm{~N}$. The weight and friction forces are of the same order of magnitude as the apparent shear forces, but for sake of clarity these forces have not been plotted in Figs 14-16.

Previous experimental work carried out by other authors provides an insight into these results. In compound channels with uniform roughness, Toebes and Sooky (1967), Sellin et al. (1993) and Shiono and Muto (1998) showed that as the overbank depth increases, the floodplain flow crosses over the main channel, so that the largest stresses appear at the horizontal interface which separates both flows at the floodplain bed level. However, Wormleaton et al. (2004a) demonstrated that when the roughness in the floodplains is larger than in the main channel, the slower flow in the floodplains is unable to cross over the main channel, so that the highest turbulent stresses occur at the vertical interface which separates the main channel and the floodplains. The results of the present research confirm the importance of the mass exchange in meandering compound channels and highlight that apparent shear forces increase when
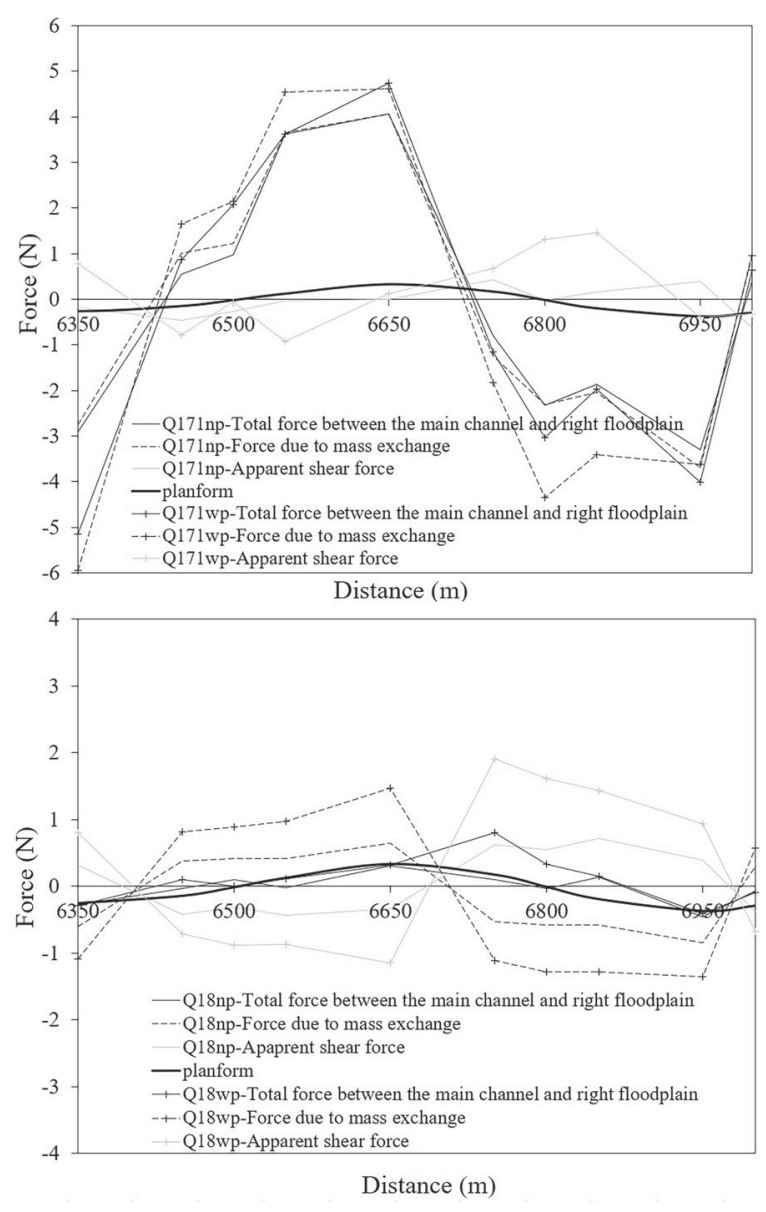

Figure 16 Comparison of total and apparent shear forces between two discharges with plants and with no plants, Q171 and Q18 
floodplains are densely vegetated, mainly due to the high velocity gradient between the sinuous main channel and vegetated floodplains.

\section{Conclusions}

Experimental observations of depth-averaged velocity distribution, discharge distribution and momentum balance between the main channel and floodplains have been presented for a sinuous compound channel with different floodplain roughness. The effects of floodplain roughness (flexible vegetation) on discharge distribution and momentum balance have also been investigated. The following conclusions can be drawn.

The velocities direction has been shown to depend on relative depth and on floodplain vegetation. For low overbank depths, the velocities in the main channel tend to follow parallel to the sinuous banks, while for large overbank depths they tend to follow the floodplain wall. In the floodplain the velocities always maintain the direction of the lateral walls. In the cases with plants, the main channel velocities are slower than the cases with same total discharge or same depth but with no plants. The reason is an increase in turbulent interaction between the main channel and floodplain flows as the roughness on the floodplains increases. The interchange of discharge between the main channel and floodplains varies along a meander wavelength. The discharge in the main channel reaches its maximum just upstream of the crossover, decreasing until the mid-distance between the crossover and the next bend apex. The floodplain roughness and the flow depth affect the maximum and minimum values of the main channel discharge but not the shape of the distribution.

The effect of the floodplain vegetation is particularly important in floodplain and main channel interaction. The momentum balance analysis shows that the momentum fluxes associated with the exchange of discharge between the main channel and the floodplains dominate over the turbulent forces at the vertical interface of separation. However, for low depths and large differences in roughness, the turbulent forces become as important as the forces due to discharge exchange. As there is little previous work reported on rivers with densely vegetated floodplains, the relative contributions of the mass exchange and turbulent interaction on flow resistance and discharge distribution between the main channel and floodplains are an essential result of this research.

The results of this work could be helpful for the development and calibration of new methods and numerical models for discharge estimation in meandering compound channels. Traditional methods for water flow analysis are inaccurate in natural rivers where the sinuosity and roughness strongly affect the flow, and new methods which include the turbulent interaction and mass exchange between sub-sections must be considered. In this study natural conditions of rivers have been modelled, giving an insight into the effects of increasing roughness and sinuosity in river restoration projects. Finally, we can conclude the importance of considering momentum transfer for the calculation of rising water levels in these projects. More research is required using large-scale data with different geometry and sinuosity in the main channel and different roughness in the floodplains.

\section{Notation}

\begin{tabular}{|c|c|c|}
\hline$\beta$ & $=$ & Boussinesq coefficient $(-)$ \\
\hline$\rho$ & $=$ & water density $\left(\mathrm{N} \mathrm{m}^{-3}\right)$ \\
\hline$\tau_{b}$ & $=$ & $\begin{array}{l}\text { bed shear stress (acting in wetted perimeter) } \\
\left(\mathrm{N} \mathrm{m}^{-2}\right)\end{array}$ \\
\hline$A_{t}$ & $=$ & total flow area of the cross section $\left(\mathrm{m}^{2}\right)$ \\
\hline$B, b$ & $=$ & section width, main channel bed width (m) \\
\hline$B_{f}$ & $=$ & floodplain width (m) \\
\hline$d$ & $=$ & distance between two consecutive sections (m) \\
\hline$d_{50}$ & $=$ & loodplain roughness $(\mathrm{mm})$ \\
\hline$g$ & $=$ & gravitational acceleration $\left(\mathrm{m} \mathrm{s}^{-2}\right)$ \\
\hline$F^{*}$ & $=$ & $\begin{array}{l}\text { total observed discharge by the sum of zonal } \\
\text { discharges calculated with Manning (-) }\end{array}$ \\
\hline$H$ & $=$ & main channel depth (m) \\
\hline$h$ & $=$ & depth of main channel below floodplain level (m) \\
\hline$S_{e}$ & $=$ & energy slope $\left(\mathrm{m} \mathrm{m}^{-1}\right)$ \\
\hline$S_{o}$ & $=$ & bottom slope $\left(\mathrm{m} \mathrm{m}^{-1}\right)$ \\
\hline$n$ & $=$ & Manning's roughness coefficient $\left(\mathrm{s} \mathrm{m}^{-1 / 3}\right)$ \\
\hline$n_{f}$ & $=$ & $\begin{array}{l}\text { Manning's roughness coefficient of floodplain } \\
\left(\mathrm{s} \mathrm{m}^{-1 / 3}\right)\end{array}$ \\
\hline$P_{w}$ & $=$ & wetted perimeter $(\mathrm{m})$ \\
\hline$Q$ & $=$ & discharge $\left(\mathrm{m}^{3} \mathrm{~s}^{-1}\right)$ \\
\hline$Q_{c}, Q_{f}$ & $=$ & main channel and floodplain discharges $\left(\mathrm{m}^{3} \mathrm{~s}^{-1}\right)$ \\
\hline$V_{c}$ & & $\begin{array}{l}\text { main channel velocity given by the Manning } \\
\text { formula }\left(\mathrm{m} \mathrm{s}^{-1}\right)\end{array}$ \\
\hline$V_{m}$ & & $\begin{array}{l}\text { mean velocity measured in the cross-section } \\
\left(\mathrm{m} \mathrm{s}^{-1}\right)\end{array}$ \\
\hline 1 & $=$ & downstream section (suffix) \\
\hline 2 & $=$ & upstream section (suffix) \\
\hline$c$ & $=$ & main channel (suffix) \\
\hline$f$ & $=$ & floodplain (suffix) \\
\hline$i$ & $=$ & individual dataset (suffix) \\
\hline$l, r$ & $=$ & left and right floodplain respectively (suffix) \\
\hline$m$ & $=$ & mean (suffix) \\
\hline
\end{tabular}

\section{References}

Bousmar, D., Omran, M., Atabay, S., \& Knight, D. W. (2009). Bed shear stress and roughness distribution in meandering compound channels. Proceeding of the 33rd IAHR Congress, Canada.

Bousmar, D., \& Zech, Y. (1999). Momentum transfer for practical flow computation in compound channels. Journal of Hydraulic Engineering, 125(7), 696-706.

Elliott, S. C. A., \& Sellin, R. H. J. (1990). SERC flood channel facility: Skewed flow experiments. Journal of Hydraulic Research, 28(2), 197-214. 
Ervine, D. A., Willetts, B. B., Sellin, R. H. J., \& Lorena, M. (1993). Factors affecting conveyance in meandering compound flows. Journal of Hydraulic Engineering, 119(12), 1383-1399.

Fernandes, J. N., Leal, J. B., \& Cardoso, A. H. (2012). Flow structure in a compound channel with smooth and rough floodplains. European Water, 38, 3-12.

Greenhill, R. K., \& Sellin, R. H. J. (1993). Development of a simple method to predict discharges in compound meandering channels. Proceedings of the Institution of Civil Engineers - Water, Maritime and Energy, 101(1), 37-44.

Huthoff, F., Roos, P. C., Augustijn, D. C. M., \& Hulscher, S. J. M. H. (2008). Interacting divided channel method for compound channel flow. Journal of Hydraulic Engineering, 134(8), 1158-1165.

Knight, D. W., \& Demetriou, J. D. (1983). Flood plain and main channel flow interaction. Journal of Hydraulic Engineering, 109(8), 1073-1092.

Kouwen, N. (1990). Modern approach to design of grassed channels. Journal of Hydraulic Engineering, 118(5), 733743.

Martín-Vide, J. P. (2001). Restoration of an urban river in Barcelona, Spain. Environmental Engineering and Policy, 2(3), 113-119.

Martin-Vide, J. P., López-Querol, S., \& Moreta, P. J. M. (2004). Improving 1D-modelling of open channel flow in compound channels. Paper presented at the conference River Flow 2004 (Vol. 1, pp. 415-422). Napoli, Italy: IAHR.

Mauchamp, A., Chauvelon, P., \& Grillas, P. (2002). Restoration of floodplain wetlands: Opening polders along a coastal river in Mediterranean France, Vistre marshes. Ecological Engineering, 18, 619-632.

McKeogh, E. J., \& Kiely, G. (1989, August). Experimental study of the mechanisms of flood flow in meandering channels. Proceedings of the 23rd IAHR Congress, Ottawa.

Moreta, P. J. M., \& Martin-Vide, J. P. (2010). Apparent friction coefficient in straight compound channels. Journal of Hydraulic Research, 48(2), 169-177.

Myers, W. R. C. (1978). Momentum transfer in a compound channel. Journal of Hydraulic Ressearch, 16(2), 139-150.

Petryk, S., \& Bosmajian, G. B. (1975). Analysis of flow through vegetation. Journal of Hydraulic Division, 101(7), 871884.

Rameshwaran, P., \& Willetts, B. B. (1999). Conveyance prediction for meandering two-stage channel flows. Proceeding of the Institution of Civil Engineers - Water Maritime and Energy, 136(4), 153-166.

Sanjou, M., \& Nezu, I. (2009). Turbulence structure and coherent motion in meandering compound open-channel flows. Journal of Hydraulic Research, 47(5), 598-610.

Sellin, R. H. J. (1964). A laboratory investigation into the interaction between the flow in the channel of a river and that over its flood plain. La Houille Blanche, 7, 793-802.
Sellin, R. H. J., Ervine, D. A., \& Willetts, B. B. (1993). Behaviour of meandering two-stage channels. Proceedings of the Institution of Civil Engineers - Water Maritime and Energy, 101(2), 99-111.

Sellin, R. H. J., \& Willetts, B. B. (1996). Three-dimensional structures, memory and energy dissipation in meandering compound channel flow. In M. G. Anderson, D. E. Walling \& P. D. Bates (Eds.), Floodplain processes (pp. 255-298). Wiley.

Shiono, K., Chan, T. L., Spooner, J., Rameshwaran, P., \& Chandler, J. H. (2009). The effect of floodplain roughness on flow structures, bedforms and sediment transport rates in meandering channels with overbank flows: Part I. Journal of Hydraulic Research, 47(1), 5-19.

Shiono, K., \& Knight, D. W. (1991). Turbulent open channel flows with variable depth across the channel. Journal of Fluid Mechanics, 222, 617-646.

Shiono, K., \& Muto, Y. (1998). Complex flow mechanisms in compound meandering channels with overbank flow. Journal of Fluid Mechanics, 376, 221-261.

Toebes, G. H., \& Sooky, A. A. (1967). Hydraulics of meandering rivers with floodplains. Journal of Waterways and Harbours Division, 93(2), 213-236.

Townsend, R. D. (1968). An investigation of turbulence characteristics in a river model of complex cross-section. Proceedings of the Institution of Civil Engineers, 40(2), 155-175.

Vionnet, C. A., Tassi, P. A., \& Martín Vide, J. P. (2004). Estimates of flow resistance and eddy viscosity coefficients for 2D modelling on vegetated floodplains. Hydrological Processes, 18, 2907-2926.

Wark, J. B., James, C. S., \& Ackers, P. (1994). Design of straight and meandering compound channels. National Rivers Authority, R\&D Report 13, UK.

Wormleaton, P. R., Allen, J., \& Hadjipanos, P. (1982). Discharge assessment in compound channel flow. Journal of Hydraulic Division, 108(9), 975-994.

Wormleaton, P. R., \& Merrett, D. J. (1990). An improved method of the calculation for steady uniform flow in prismatic main channel/flood plain sections. Journal of Hydraulic Resesarch, 28(2), 157-174.

Wormleaton, P. R., Sellin, R. H. J., Bryant, T., Loveless, J. H., Hey, R. D., \& Catmur, S. E. (2004a). Flow structures in a two-stage channel with a mobile bed. Journal of Hydraulic Research, 42(2), 145-162.

Wormleaton, P. R., Sellin, R. H. J., Bryant, T., Loveless, J. H., Hey, R. D., \& Catmur, S. E. (2004b). Conveyance in a two-stage meandering channel with a mobile bed. Journal of Hydraulic Research, 42(5), 493-506.

Wright, P. R., \& Carstens, H. R. (1970). Linear momentum flux to overbank sections. Journal of Hydraulics Division, 96(9), 1781-1793.

Zheleznyakov, G. V. (1971). Interaction of channel and floodplain streams. Proceedings of the 14th IAHR Congress (pp. 145-148). Paris, 5. 